\title{
Cross-serial dependencies in Dutch: Testing the influence of NP type on processing load
}

\author{
EDITH KAAN \\ University of Florida, Gainesville, Florida \\ and \\ NADA VASIĆ \\ Utrecht University, Utrecht, The Netherlands
}

\begin{abstract}
We tested the cross-linguistic generalizability of three models of sentence processing complexityLewis (1996), Gibson (1998, 2000), and Gordon (Gordon, Hendrick, \& Johnson, 2001; Gordon, Hendrick, \& Levine, 2002) - by investigating the on-line processing of cross-serial dependencies in Dutch. The number of subject-verb relations in a clause was manipulated, as well as type of noun phrase (indexical pronouns vs. proper names or full definite NPs). Several of our findings diverged from Gibson's model: Processing difficulty at the verbs was not affected by the use of proper names versus first- and second-person pronouns; an increase at the first verb was seen for full NPs versus pronouns in 3-verb constructions, which was predicted by the Gibson model, but is in contrast to Lewis's model. These findings are best explained within the framework of similarity-based inference models (Gordon et al., 2001; Gordon et al., 2002), according to which the number of similar NPs affects processing difficulty at the point of retrieval, and not specifically their discourse status or syntactic function.
\end{abstract}

One of the aims of sentence processing research is to develop a model of sentence complexity and working memory. Although psycholinguists agree that cross-linguistic data need to be taken into account, most models have been based primarily on data from English. For instance, an important observation in the development of complexity models is that double center embeddings in English such as The rat the cat the dog bit chased ate the malt are harder to process than single embeddings such as The rat the cat chased ate the malt or right-branching sentences such as The dog bit the cat that chased the rat that ate the malt. Many different accounts of these facts have been proposed, among them models that define conditions of processing difficulty and breakdown in terms of the number of open clauses (Kimball, 1973), self-embedding (Miller \& Chomsky, 1963), unresolved dependencies of same type (Stabler, 1994), the number of nodes that can be postulated on the basis of incoming information (Hawkins, 1994), unre-

This research was initiated while E.K. was a Grotius postdoctoral fellow at the Utrecht Institute for Linguistics-OTS. E.K. is currently supported by JSMF 20002044. N.V. is supported by the Pioneer Project "Comparative Psycholinguistics," which is funded by the Netherlands Organization for Scientific Research (NWO). We would like to thank Inge-Marieke Hammen, Martine Schepers, Jasmine Soori-Arachi, and Rianne Vlooswijk for their help, and Frank Wijnen for discussion. Correspondence should be addressed to E. Kaan, Program in Linguistics, University of Florida, Box 115454, Gainesville, FL 32611 (e-mail: kaan@ufl.edu). solved dependencies and distance between the dependent elements (Gibson, 1998, 2000), and interference by similarity (Bever, 1970; Gordon, Hendrick, \& Johnson, 2001; Gordon, Hendrick, \& Levine, 2002; Lewis, 1996). However, to date, only a few studies have been done on processing difficulty in center embeddings in languages other than English (Hindi: Vasishth, 2002; Korean: Hagstrom \& Rhee, 1997; Japanese: Babyonishev \& Gibson, 1999; Lewis \& Nakayama, 2001; German and Dutch: Bach, Brown, \& Marslen-Wilson, 1986; Dickey \& Vonk, 1996). The goal of the present study was to test three current models of processing complexity using a unique syntactic construction in Dutch.

Dutch provides a challenge for complexity models because it allows cross-serial dependencies between noun phrases (NPs) and verbs. This is illustrated in Figure 1. The dependencies between the NPs and the verbs in Dutch, as indicated by the lines in Figure 1, cross each other: The linear order of the subject NPs (NP1-NP2-NP3) is the same as that of their corresponding verbs (V1-V2V3). This is different from the center embeddings that have been studied in English, in which the dependencies are nested; that is, the linear order of the verb phrases is the reverse of that of the corresponding NPs, such as, for example, NP1 (The rat)-NP2 (the cat)-NP3 (the dog)-V3 (bit)-V2 (chased)-V3 (ate the malt).

An off-line study of Dutch cross-serial dependencies conducted by Bach et al. (1986) showed that native speakers of Dutch have more difficulty processing sentences 
A

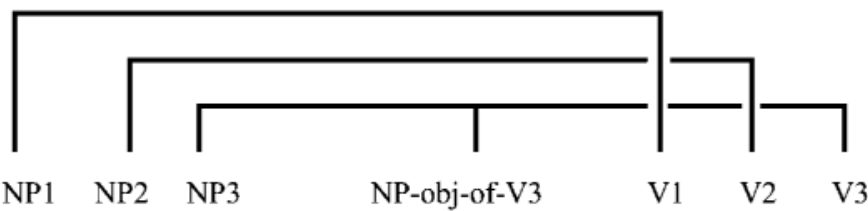

(dat) Aad Jantje de lerares de knikkers liet helpen opruimen

(that) Aad Jantje the teacher the marbles let help collect

"(That) Aad let Jantje help the teacher to collect the marbles"

B

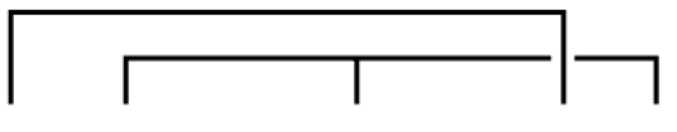

NP1 NP2 NP-obj-of-V2 $\quad$ V1 V2

(dat) Jantje de lerares de knikkers hielp opruimen

(that) Jantje the teacher the marbles helped collect

"(That) Jantje helped the teacher collect the marbles"

Figure 1. Illustration of cross-serial dependencies between NPs and verbs in Dutch. The lines and numbers indicate which NP belongs to which verb. The Dutch example is followed by a literal translation in English, which in turn is followed by an English paraphrase. A, a 3-verb structure; B, a 2-verb structure. Obj, object; V, verb.

with three subjects and three verbs (as in Figure 1A) than sentences containing two verbs and two subjects (Figure 1B). However, 3-verb sentences in Dutch are somewhat easier than their equivalents in German using nested, rather than crossed, dependencies (Bach et al., 1986). This observation has been very influential in the development of complexity metrics. However, little is known about how the Dutch cross-serial dependencies are processed on-line and what factors influence the ease of processing (see Dickey \& Vonk, 1996, for one exception). The aim of the present study was therefore to investigate the on-line processing of Dutch cross-serial dependencies to further test current models of processing difficulty. In this paper, we focus on three recent proposals: Lewis (1996), Gibson (1998, 2000), and Gordon et al. (Gordon et al., 2001; Gordon et al., 2002).

\section{Gibson (1998, 2000)}

In the model proposed by Gibson $(1998,2000)$, processing load has two components: memory cost and integration cost. At each incoming word, the parser generates predictions concerning syntactic categories to come; for example, a subject NP predicts a verb. These predictions are stored in working memory until they are satisfied by new input, at which point integration occurs. Storage (memory) and integration are separable in a quantified way. Memory load is a function of the number of predicted categories in memory (Gibson, 1998, 2000). Integration cost is a function of the number of integrations, and the distance between the point of integration (e.g., the verb) and the point at which the predictions were first made (e.g., the subject NP). As a first distance metric, Gibson proposed quantifying distance as the number of new discourse referents that need to be set up in the current discourse model. For instance, in isolated sentences, full definite NPs (e.g., the king), proper names (John), and verbs refer to entities and events that have not been mentioned before. This means that a new discourse entity or event needs to be set up in the discourse representation. Processing such an NP or verb therefore requires more processing resources, and makes retention of predictions and integration more difficult than retention of, for example, first- and second-person (or indexical) pronouns, such as $I, y o u$, or we, which refer to entities that can be assumed to be always present in a discourse (for a modification of this metric, see Warren \& Gibson, 2002).

Gibson's model makes the following predictions with respect to the processing load in 3 -verb versus 2 -verb cross-serial dependencies in Dutch. First, memory load will increase with each incoming NP, since each incoming NP predicts a verb (or a trace at the verb, in the case of an object NP). As we will further elaborate on below, some reanalysis may take place while an individual is processing the NP sequence (from direct object to indirect object to subject). However, each incoming NP will be associated with a verb, either as subject or as another argument that needs to be associated with a verb to receive a thematic role, which will lead to an increase in memory load. Since 3-verb sentences (Figure 1A) contain more NPs than 2-verb sentences (Figure 1B), memory load before the verbs will be higher in the 3 -verb sentences. The second prediction is that integration at the verbs is more 
costly in the 3-verb than in the 2-verb condition (possibly with the exception of V1; see Gibson, 1998). In the 3-verb condition, more integrations take place than in the 2-verb conditions, since more verbs need to be integrated with their subject NPs. These integrations are more costly, since the distance between the subjects and their verbs is longer (more intervening NPs and verbs) and predictions of more upcoming verbs need to be retained in memory during integration. For instance, to integrate V2 and NP2 in the 3 -verb condition (Figure 1A), two NPs (NP3, NP object-of-V3), and one verb (V1) need to be crossed. Simultaneously, the prediction of $\mathrm{V} 3$ needs to be retained in working memory. In contrast, when V2 is integrated with NP2 in 2-verb sentences (Figure $1 \mathrm{~B})$, only one $\mathrm{NP}\left(\mathrm{NP}_{\text {object-of- } \mathrm{V} 2}\right)$ and one verb (V1) need to be crossed. No following verb is predicted, so there is no memory load associated with retaining this prediction. Reading times at the verbs should therefore be shorter in the 2-verb than in the 3-verb sentences. A third prediction of the Gibson model, which is crucial for distinguishing it from other models, is that processing load is affected by the nature of the NPs: If the intervening NPs are first- or second-person pronouns, integration costs at the verbs will be less than when the NPs are proper names or full definite NPs, since first- and second-person pronouns do not introduce any new discourse referents and hence do not impose any memory load when they intervene between an NP and its verb. Moreover, a larger effect of NP type is expected in 3-verb relative to 2-verb sentences, since there are more NPs that intervene between the verbs and their appropriate arguments.

\section{Lewis (1996)}

Lewis (1996) attributes parsing difficulty to interference effects in working memory. Interference in sentence processing occurs if elements with the same syntactic function (e.g., subject, object) are retained in memory and need to be retrieved. As applied to the Dutch cross-serial dependencies, the following predictions can be made. Retrieval of the appropriate NPs is harder in 3-verb than in 2verb conditions because NP1, NP2, and NP3 in the 3 -verb condition can all qualify as subjects, leading to maximal interference. ${ }^{1}$ For instance, at V1 in Figure 1A, both NP2 and NP3 interfere with the retrieval of NP1. In the 2 -verb condition, on the other hand, retrieval of NP1 suffers only from interference from NP2. This will lead to an increase in difficulty for the 2 -verb versus 3 -verb conditions at the verbs, as is also predicted by the Gibson model (Gibson, 1998, 2000). However, in crucial contrast to the Gibson model, the model proposed by Lewis does not predict any differences at the verb caused by the use of different types of NP. Therefore, no differences at the verbs are expected between conditions in which full NPs or proper names are used, relative to conditions with indexical pronouns.

\section{Gordon et al. (Gordon et al., 2001; Gordon et al., 2002)}

A different account of parsing difficulty through interference has been put forward by Gordon et al. (Gordon et al.,
2001; Gordon et al., 2002). According to this model, integration difficulty at the verbs is not, or not primarily, caused by interference through similarity of syntactic function, as in the Lewis model, but through similarity in general. In this view, interference is strongest when the element to be retrieved is surrounded by other elements that are similar along multiple dimensions, such as type of NP, case, or semantic features. In contrast to Gibson, and similar to Lewis, Gordon et al. predict no differences between conditions with full NPs or proper names relative to indexical pronouns. However, as opposed to Lewis, Gordon et al. posit that NP type can affect processing difficulty: Processing is easy if the NPs in the sentence are of different types; processing is hard if the NPs are of the same type.

\section{Revision}

In the preceding discussion of the complexity metrics, it is assumed that NP1, NP2, and NP3 are immediately analyzed as subjects. This is not necessarily the case. Since Dutch is not case marked, an alternative and more plausible view is that the simplest structure is assumed with each incoming NP (see Dickey \& Vonk, 1996; Vasishth \& Kruijff, 2000). When a 3-verb sentence (Figure 1A) is processed from left to right, NP2 is initially interpreted as the direct object of a transitive predicate of which NP1 is the subject (as in dat Aad Jantje schopt; "that Aad kicks Jantje"). At NP3 a ditransitive predicate is the simplest option, which entails reanalysis of NP2 as an indirect object and NP3 as a direct object (as in dat Aad Jantje de lerares aanwijst; "that Aad points out the teacher to Jantje"). The final NP is evidence that a second predicate is involved. NP2 may then be reanalyzed as the subject of the second verb, with NP3 and the final NP as its indirect and direct object, respectively (as in dat Aad Jantje de lerares de knikkers liet geven; "that Aad made Jantje give the marbles to the teacher"). This 2-VP analysis proves to be incorrect when V2 or V3 appears not to be a ditransitive verb, at which point the sentence is revised again. However, even under such a revision account, the models discussed above make different predictions concerning the effect of NP type on the difference between 2-verb and 3 -verb sentences at the verbs. Establishing the correct dependencies between the verbs and the NPs requires crossing other NPs. Hence, Gibson would predict an increase in reanalysis difficulty at the penultimate or final verb for full NPs relative to indexical pronouns. According to Lewis (1996), on the other hand, the type of NPs is not relevant, and hence only a general increase in reading times is predicted at the penultimate or final verb for 3 -verb versus 2 -verb sentences. Finally in the model proposed by Gordon et al. (Gordon et al., 2001; Gordon et al., 2002), the NP type manipulation will have an effect only if it causes an increase in the number of NPs of a similar type.

\section{EXPERIMENT 1}

The aim of Experiment 1 was to distinguish among the models with a self-paced reading study contrasting 3-verb 
and 2-verb clauses containing indexical pronouns and proper names.

\section{Method}

Participants. Forty native speakers of Dutch (6 male, age 1834 years, mean age 22.6) were paid for participation. Most of them were undergraduate students at the University of Utrecht. None of them participated in the materials pretest described below.

Materials. In this and the following experiment we tested sentences of the format illustrated in Table 1 . The 2-verb sentence started with a prepositional phrase containing the same NP that served as the subject of the first verb in the 3 -verb conditions $\left(\mathrm{NP}_{\mathrm{i}}\right)$. This was to ensure that the 2-verb and 3-verb conditions were as similar as possible in terms of the number of NPs denoting human entities and the number of NPs between the auxiliary and the verbs. The verbs in the 2-verb condition were the same as the second and third verbs in the 3 -verb condition. This was to equate the meaning of the sentences as much as possible, especially with respect to the thematic roles of the NPs after the auxiliary.

In Experiment $1, \mathrm{NP}_{\mathrm{j}}$ and $\mathrm{NP}_{\mathrm{k}}$ in Table 1 were either first/second person pronouns or proper names. Examples of the four conditions are given in Table 2 . The slashes and numbers indicate the segmentation used for stimulus presentation and analysis.

In the proper name conditions, one male and one female name were used, in different orders. In the pronoun conditions, both singular and plural pronouns were used to introduce some variation in the experimental items. The first $\mathrm{NP}$ of the sentence $\left(\mathrm{NP}_{\mathrm{i}}\right)$ was always a full NP. The object NP $\left(\mathrm{NP}_{\text {object-of-k }}\right)$ immediately preceding the verbs was a full NP referring to a nonhuman entity. To control for potential differences in plausibility, an off-line plausibility rating was conducted. We used simple paraphrases of the sentences to avoid any effects of processing difficulty on the plausibility judgment. For instance, the first sentence in Table 2 was paraphrased as Met aanwijzingen van de leider heeft Paul Sonja geleerd het kompas te gebruiken tijdens de bergtocht (With the leader's directions, Paul taught Sonja to use the compass during the hike), and the 3-verb version as De leider heeft Paul geholpen om Sonja te leren het kompas te gebruiken tijdens de bergtocht (The leader has helped Paul to teach Sonja to use the compass during the hike). Paraphrases of 43 potential experimental items were pseudorandomly intermixed with 56 fillers, which differed in plausibility. Four lists were constructed according to a Latin square design. Forty-eight native speakers of
Table 1

Format of the Experimental Items

Segment

\begin{tabular}{|c|c|c|c|c|c|c|c|c|c|c|}
\hline & \multicolumn{10}{|c|}{ Segment } \\
\hline & 1 & 2 & 3 & 4 & 5 & 67 & 8 & 9 & 10 & 11 \\
\hline 3-verb & & Aux & $\mathrm{NP}_{\mathrm{j}}$ & $\mathrm{NP}_{\mathrm{k}}$ & $\mathrm{NP}_{\text {obj-of-k }}$ & $\begin{array}{ll}V_{i} & V_{j}\end{array}$ & $\overline{V_{k}}$ & $P$ & DET & $\overline{\mathrm{NP}}$ \\
\hline 2 -verb & $\mathrm{PP}+\mathrm{NP}$ & Aux & $\mathrm{NP}_{\mathrm{j}}$ & $\mathrm{NP}_{\mathrm{k}}$ & $\mathrm{NP}_{\text {obj-of-k }}$ & $-V_{j}$ & $V_{k}$ & $\mathrm{P}$ & DET & NP \\
\hline
\end{tabular}

Note-Subscripts indicate which NP belongs to which verb. AUX, auxiliary; DET, determiner; obj, object; $\mathrm{P}$, preposition; $\mathrm{PP}$, prepositional phrase.

Dutch, all students at Utrecht University, were asked to rate the situation expressed by the sentence in terms of naturalness /plausibility, using a scale from 1 (impossible /unnatural) to 5 (possible/natural). On the basis of these ratings, 32 item sets were selected for the reading experiment. The plausibility ratings of the four paraphrases of these 32 items showed no interaction between the number of verbs and the type of NPs used ( $p s>.1$ ), although the 2-verb conditions were rated as more natural than the 3 -verb conditions $[F(1,31)=$ $19.19, p<.001]$, and the proper name conditions were rated better than the pronoun conditions $[F(1,31)=9.08, p<.074$; means: 3 -verb proper name: 4.0 ; 3 -verb-pronoun:3.7; 2-verb proper name: 4.1; 2-verb-pronoun:4.0]. The selected materials and the mean plausibility ratings for each item in this and the next experiment have been submitted to the Psychonomic Society's Norms, Stimuli, and Data Archive, available after August 1, 2004 at http://www.psychonomic. org. Sixty-four filler items were constructed, yielding a total of 96 items. Half of the fillers started with a prepositional phrase. Many contained proper names and pronouns to resemble the experimental items to some extent. Half of the materials (experimental and fillers) were followed by a comprehension question. The nature of the answers (yes/no, or choice among two options) and the position of the correct response were balanced across experimental conditions. Four subject lists were created according to a Latin square design. In the lists, the 32 item sets were divided into four groups of eight sets each. Each item group was assigned to one of the four conditions within a subject list, with the conditions rotating over the item groups across the lists. Fillers and experimental items were automatically pseudorandomized in a different order for each participant.

Procedure. Stimulus presentation and data acquisition were controlled by the DMASTR software developed by K. I. Forster and J. C. Forster. The task was a self-paced reading task using a noncumula-

Table 2

Examples of the Four Conditions in Experiment 1

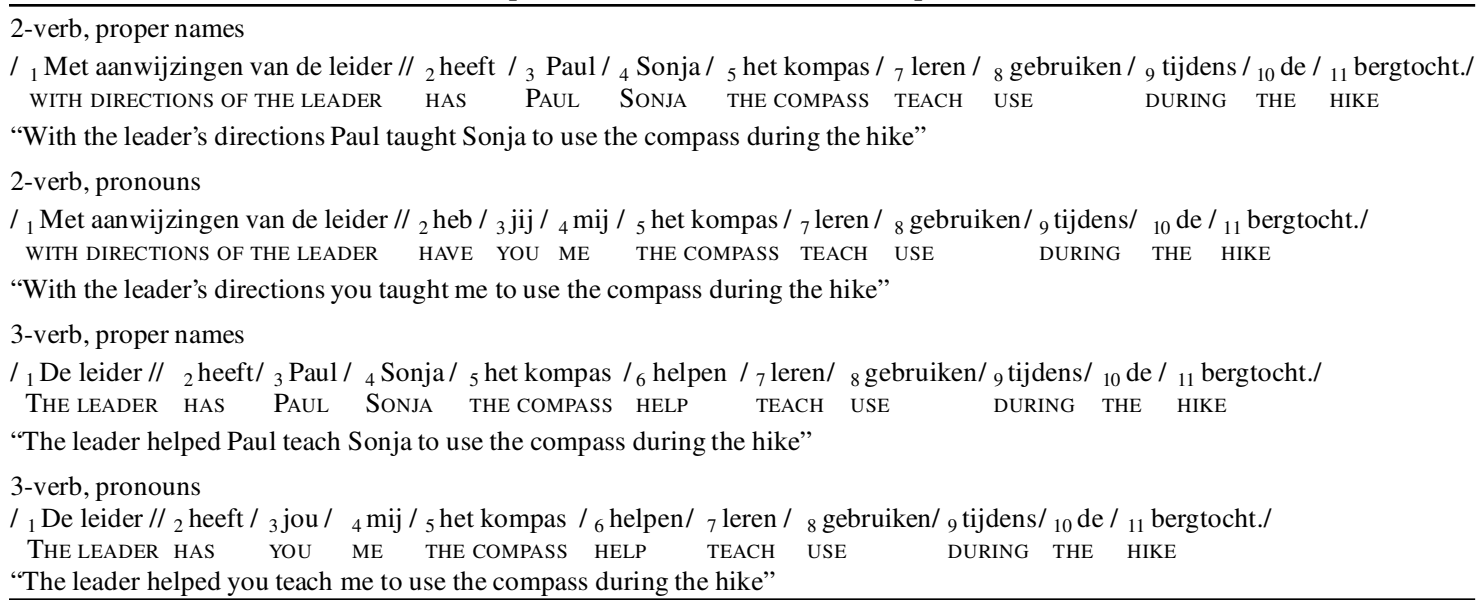

Note- “"” indicates the segmentation used in the presentation; "//" indicates a line break. A literal English translation as well as an English paraphrase immediately follows each Dutch sentence. 
tive, moving window display. The segmentation used is indicated by slashes (/) in Table 2. Participants were individually tested in a sound-attenuating booth. The participant initiated a trial by pressing the space bar on the keyboard. Five hash marks were presented where the first word would appear. The first word and subsequent segments could be displayed by pressing the left or right shift key, depending on the participant's preferred hand. Since some sentences were too long to fit on one line, and since we wished to keep the position of auxiliary and following words as consistent as possible across the four experimental conditions, a line break occurred after the first segment (indicated by "//" in Table 2). Participants were instructed to read at normal speed and to answer the questions as accurately as possible. Before the actual experiment, a practice session with eight sentences was run to familiarize the participants with the task.

Analysis. Reading times shorter than $30 \mathrm{msec}$ and longer than $4,000 \mathrm{msec}$ were dropped from the analysis. Next, reading times shorter (longer) than the mean minus (plus) twice the standard deviation for each position and condition were trimmed to the means minus (plus) twice standard deviation for each subject (affecting $5.8 \%$ of the data). ${ }^{2}$ Mean reading times at positions of interest were analyzed using an SPSS GLM repeated measurements procedure, for both subject $\left(F_{1}\right)$ and item $\left(F_{2}\right)$ means, with number of Vs (2 vs. 3 verbs) and NP type (proper name vs. pronoun) as within-subjects (item) factors and subject list (item group) as the between-subjects (item) factor. We conducted analyses on the following segments: (1) Segment 5, to investigate memory load before the verbal complex; (2) first verb (Segment 6 in the 3-verb condition; Segment 7 in the 2-verb condition); (3) penultimate verb (Segment 7); (4) last verb (Segment 8); (5) positions after the verbs (Segments 9-11). All trials were included in the reading times analyses, regardless of the response to the comprehension questions.

\section{Results}

Questions following experimental items were answered correctly in $88 \%$ of the cases, suggesting that participants were paying attention. Because the questions were not designed to systematically probe the correct assignment of nouns to verbs, no statistical analyses were conducted. Mean reading times for positions in the experimental sentences are given in Table 3 and Figure 2.

Position before the verb (Segment 5). As can be seen in Figure 2, reading times increased with each incoming $\mathrm{NP}$ and were longer for proper names than for pronouns. Since the differences before Segment 5 were confounded by frequency and physical differences between the pronoun and proper name conditions, we focused on Segment 5 , the NP immediately preceding the first verb. At this position, the proper name conditions were read more slowly than the pronoun conditions $\left[F_{1}(1,36)=6.51, p<\right.$ $\left..05 ; F_{2}(1,28)=6.50, p<.05\right]$. Furthermore, the 3 -verb conditions were read more slowly than the 2 -verb conditions $\left[F_{1}(1,36)=31.99, p<.001 ; F_{2}(1,28)=37.43, p<\right.$ $.05]$. Numerically the difference in reading times between the proper name and pronoun conditions was largest in the 2 -verb condition, but this interaction did not reach significance $\left[F_{1}(1,36)=2.98, p=.098 ; F_{2}(1,28)=4.07, p=\right.$ .053].

Verbs (Segments 6-8). The first verb in the 3-verb conditions (Segment 6) was read more slowly than the first verb in the 2-verb conditions (Segment 7), but this effect was significant only by items $\left[F_{1}(1,36)=2.83 ; p=\right.$ $\left..101 ; F_{2}(1,28)=5.84, p<.05\right]$. No effects were significant at the penultimate verb (Segment 7 for both 3- and 2verb conditions). The final verb (Segment 8 ) was read more slowly in the 3 -verb than in the 2 -verb conditions $\left[F_{1}(1,36)=5.86, p<.05 ; F_{2}(1,28)=6.73, p<.05\right]$. None of the three verb positions showed an interaction of NP type by number of Vs [first verb, $F_{1}(1,36)=.32, p=.57$; $F_{2}(1,28)=.49, p=.49$; penultimate verb, $F_{1}(1,36)=.66$, $p=.42 ; F_{2}(1,28)=.86, p=.36$; final verb, $F_{1}(1,36)=.02$, $\left.p=.90 ; F_{2}(1,28)=.00, p=.99\right]$, in contrast to what was predicted on the basis of Gibson $(1998,2000)$. A power analysis of the interaction effect showed that the effect needed to be at least $100 \mathrm{msec}$ for it to be detected under the current conditions of the experiment, rather than the $24 \mathrm{msec}, 33 \mathrm{msec}$, and $5 \mathrm{msec}$ we found at the first, penultimate, and final verbs, respectively. The present size of the interaction effect is so small that we would need more than 784,392 , and 14,800 participants to obtain $80 \%$ power to detect the effect at the first, penultimate, and final verbs, respectively, which is far beyond general practice in psycholinguisticresearch. Although one can never be sure that an effect is absent, the present data do suggest that using proper names or indexical pronouns has a very minimal effect on the difference in processing difficulty at the verbs in 3-verb versus 2 -verb constructions.

Positions after verb (Segments 9-11). The 3-verb conditions continued to be read more slowly than the 2verb at Segment 9 (the preposition) $\left[F_{1}(1,36)=12.68\right.$, $\left.p<.001 ; F_{2}(1,28)=23.02, p<.001\right]$. At Segment 10 (the determiner), the proper name condition was read

Table 3

Mean Reading Times (in Milliseconds) and Standard Deviations (Experiment 1)

\begin{tabular}{|c|c|c|c|c|c|c|c|c|c|c|c|c|c|c|}
\hline & \multicolumn{2}{|c|}{$\begin{array}{c}\mathrm{NP}_{\mathrm{obj}-\mathrm{of}-\mathrm{k}} \\
\text { (the compass) } \\
5\end{array}$} & \multicolumn{2}{|c|}{$\begin{array}{c}\mathrm{V}_{\mathrm{i}} \\
\text { (help) } \\
6 \\
\end{array}$} & \multicolumn{2}{|c|}{$\begin{array}{c}\mathrm{V}_{\mathrm{j}} \\
\text { (teach) } \\
7 \\
\end{array}$} & \multicolumn{2}{|c|}{$\begin{array}{c}\mathrm{V}_{\mathrm{k}} \\
(\text { use }) \\
8 \\
\end{array}$} & \multicolumn{2}{|c|}{$\begin{array}{c}\mathrm{P} \\
(\text { during) } \\
9\end{array}$} & \multicolumn{2}{|c|}{$\begin{array}{c}\text { DET } \\
(\text { the }) \\
10\end{array}$} & \multicolumn{2}{|c|}{$\begin{array}{c}\mathrm{N} \\
\text { (hike) } \\
11 \\
\end{array}$} \\
\hline & $M$ & $S D$ & $M$ & $S D$ & $M$ & $S D$ & $M$ & $S D$ & $M$ & $S D$ & $M$ & $S D$ & $M$ & $S D$ \\
\hline $3 \mathrm{~V}-\mathrm{PN}$ & 781 & 244 & 629 & 271 & 619 & 240 & 712 & 362 & 578 & 180 & 432 & 129 & 635 & 206 \\
\hline $3 \mathrm{~V}$-pro & 776 & 340 & 604 & 209 & 585 & 211 & 693 & 304 & 579 & 170 & 458 & 120 & 627 & 190 \\
\hline $2 \mathrm{~V}-\mathrm{PN}$ & 680 & 219 & - & - & 571 & 198 & 635 & 226 & 523 & 124 & 441 & 123 & 592 & 183 \\
\hline $2 \mathrm{~V}$-pro & 590 & 186 & - & - & 570 & 259 & 621 & 237 & 510 & 109 & 430 & 132 & 594 & 175 \\
\hline
\end{tabular}

Note-3V-PN, 3-verb, proper names; 3V-pro, 3-verb, pronouns; 2V-PN, 2-verb, proper names; 2V-pro,

2 -verb, pronouns. 


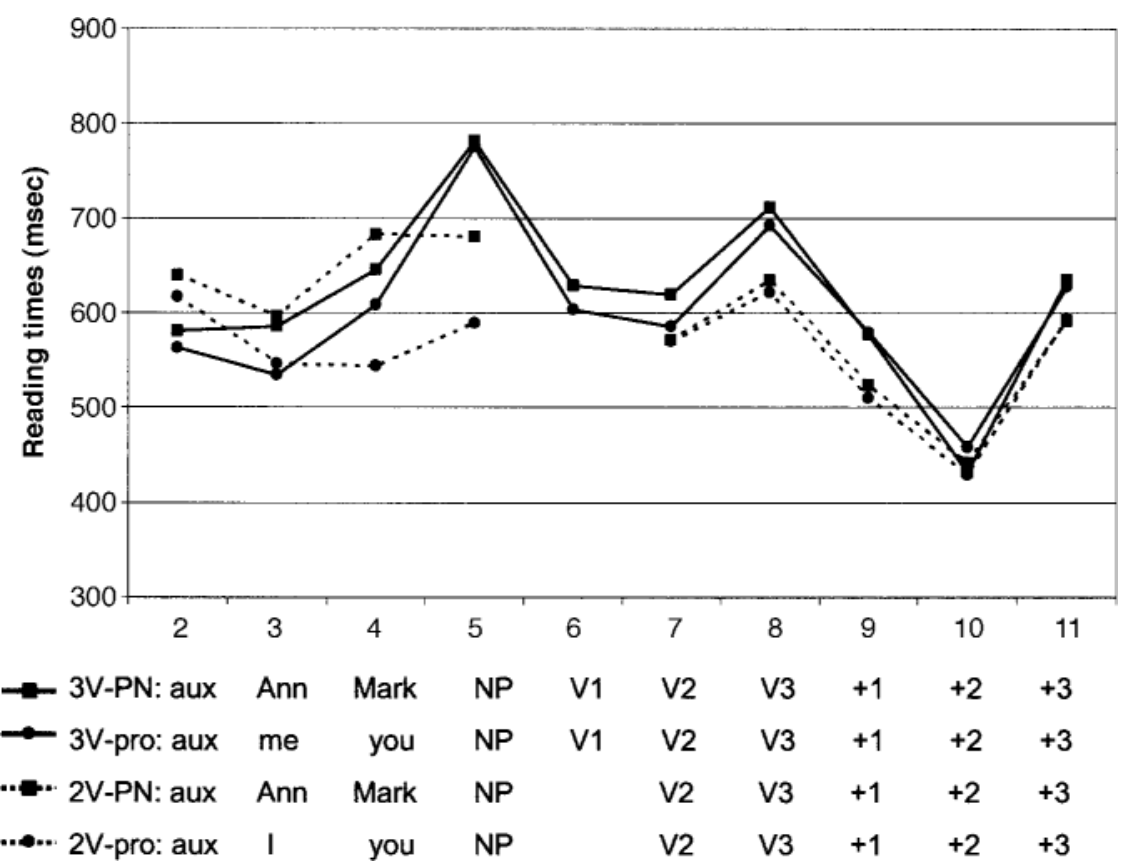

Figure 2. Experiment 1: Reading times in milliseconds for Segments 2-11 for each of the four conditions. Solid line, 3-verb conditions; dotted, 2-verb; bullets, proper names; squares, indexical pronouns. $V$, verb; $+1,+2,+3$, first, second, third segment after the last verb.

faster than the pronoun condition in the 3 -verb conditions [NP type by number of Vs: $F_{1}(1,36)=4.242, p<.05$; $\left.F_{2}(1,28)=4.377, p<.05\right]$. The direction of this difference was the opposite of what would be expected at the verbs, assuming the metric proposed by Gibson (1998).

\section{Discussion}

The type of NP affected reading times at the NP position before the verbs: The proper name conditions were read more slowly than the pronoun conditions. This observation is compatible with the memory component of the Gibson (1998) model: Proper names are more costly in terms of memory load than indexical pronouns, because proper names but not indexical pronouns introduce new discourse referents. Furthermore, at the position before the verbs, the 3-verb condition (with four NPs) was read more slowly than the 2 -verb condition (three NPs). This can also be accounted for in the Gibson model: With each incoming NP, memory load increases, since each NP predicts a verb or other syntactic category downstream. However, as noted in the introduction, increasing reading times at the NPs may also be due to revision of the structure built thus far: The NP before the verb will trigger revision from a ditransitive structure (one clause final verb) to a structure with at least two verbs (e.g., one causative, one ditransitive). The effects before the verbs are therefore not necessarily due to differences in memory load. Further, the possibility that the difference between the 2- and 3-verb conditions are partly due to strategic differences cannot be excluded, since the 3 -verb sentences were the only sen- tences in the experiment with four NPs. However, a similar pattern of differences between 2- and 3-verb sentences was reported in a previous study (Dickey \& Vonk, 1996). This study also contained items in which a sequence of four NPs was followed by two verbs (one ditransitive). This suggests that the increase in reading times in the present 3 -verb conditions is not completely strategic.

The longer reading times at the preverbal positions for the proper name versus the pronoun sentences in the 2 -verb conditions are rather unexpected. A possible explanation is that the fronted prepositional phrase in the 2-verb conditions needs to be stored in memory until it can be integrated with a verb phrase or inflectional phrase (see, e.g., Bennis \& Hoekstra, 1989; Koster, 1975, for a syntactic analysis in terms of movement), and that, following Gibson, storage is harder if the intervening elements are proper nouns rather than indexical pronouns. If this is on the right track, one must also assume that (1) the storage of information associated with one PP and three NPs is less costly than that of four NPs (to account for the main effect of number of Vs at the final NP); (2) that the type of intervening material has an effect only when memory load is moderate (to account for the fact that the type of NP affects processing cost in the 2-verb cases, but not in the 3 -verb cases). The present experiment does not provide information to further test this. We would therefore like to leave these issues to future research.

Let us now turn to the verbs. The verbs are in the positions where integration occurs between the V and the NPs that belong to it. Reading times at the verbs were longer 
in the 3-verb relative to the 2-verb conditions, replicating previous observations (Dickey \& Vonk, 1996). However, this difference was not significantly affected by the type of NPs preceding the verbal complex, in contrast to what was predicted by the Gibson model. This insensitivity to NP type at the verbs is compatible with the models proposed by Lewis (1996) and Gordon et al. (2001; Gordon et al., 2002). In these models the exact type or discourse status of the NP does not affect processing difficulty; rather, the similarity with respect to the syntactic functions of the NPs (Lewis) or the presence of other NPs of the same type (Gordon et al.) causes interference.

\section{EXPERIMENT 2}

The aim of Experiment 2 was to further distinguish the three models of processing difficulty. Experiment 2 used the same constructions as Experiment 1, except that firstand second-person pronouns were contrasted with full definite NPs, such as the king. According to the model proposed by Gibson $(1998,2000)$, full NPs have the same effect as proper names, since both introduce new discourse entities and should make integration at the verbs more costly. Any difference in results between Experiments 1 and 2 is therefore problematic for this model. The design of Experiment 2 also allowed us to further distinguish between the interference models proposed by Lewis and by Gordon et al. Lewis's model does not predict an interaction between the type of NP and the number of verbs, since interference is not sensitive to the type of NP, according to this model. This is similar to the predictions for Experiment 1. The model proposed by Gordon et al., on the other hand, does predict a difference. The full-NP conditions will contain a sequence of three similar NPs: $\mathrm{NP}_{\mathrm{j}}$, $\mathrm{NP}_{\mathrm{k}}$, and $\mathrm{NP}_{\text {obj-of } \mathrm{Vk}}($ Table 1) are all full NPs. In the pronoun conditions, on the other hand, $\mathrm{NP}_{\mathrm{j}}$ and $\mathrm{NP}_{\mathrm{k}}$ are pronouns, whereas $\mathrm{NP}_{\text {obj-of }} \mathrm{Vk}$ is a full NP. This means there is more interference through similarity in the full NP than in the pronoun cases, which would cause processing difficulty, especially in the 3 -verb conditions.

\section{Method}

Participants. Forty native speakers of Dutch (all females, age 19-38 years, mean age 21.5) were paid for participation. All were undergraduate students at the University of Utrecht. None of them had participated in Experiment 1 or in any of the materials pretests.

Materials. A new set of materials was constructed of the format shown in Tables 1 and 2, except that $\mathrm{NP}_{\mathrm{j}}$ and $\mathrm{NP}_{\mathrm{k}}$ were full definite NPs (full-NP conditions) rather than proper names, and that the first NP in the sentence was always a proper name. An example of the 2verb full NP condition is Met aanwijzingen van Jan heeft de padvinder de jongen het kompas leren gebruiken tijdens de bergtocht (Lit: With directions of John has the scout the boy the compass teach use during the mountain hike; With John's directions, the scout has taught the boy to use the compass during the mountain hike); an example of the 3-verb full NP condition is Jan heeft de padvinder de jongen het kompas helpen leren gebruiken tijdens de bergtocht (Lit: John has the scout the boy the compass help teach use during the mountain hike; John has helped the scout to teach the boy to use the compass during the mountain hike). Materials were pretested for plausibility in the same way as described for Experiment 1. Fortythree native speakers of Dutch rated 52 potential experimental items among 52 fillers. Thirty-two item sets were selected such that the plausibility ratings of the four paraphrases of these items showed no interaction between the number of verbs and the types of NP used $(p s>2)$, although conditions with full NPs were rated as less natural than the pronoun conditions $[F(1,31)=11.46, p<.01]$; and 2 -verb conditions were rated better than 3 -verb conditions $[F(1,31)=$ 7.26, $p<.05$; means: 3-verb pronoun, 4.3; 3-verb-full NP, 4.0; 2-verb pronoun, 4.4; 2-verb-full NP, 4.1]. Experimental items were interspersed among 64 filler materials. Four subject lists were constructed according to a Latin square design. The order of the items and fillers was pseudorandomized differently for each participant. Each item had a yes/no comprehension question associated with it. Questions occurred randomly after half of the items, as determined by the stimulus presentation program. Each participant received a different combination of questions.

Procedure. The testing procedure was similar to that described in Experiment 1, except that an in-house stimulus presentation and acquisition program developed by Theo Veenker was used, running on a UNIX platform (http://www.let.uu.nl/ theo.veenker/personal/). In contrast to Experiment 1 , no line breaks were used since each item fitted on one line of the screen.

Analysis. One participant was dropped from analysis because the mean reading times for this participant exceeded the mean reading times of all participants by more than $2 \mathrm{SD}$. The analysis procedure was the same as in Experiment 1. The cutoff procedure affected $5.6 \%$ of the data.

\section{Results}

Comprehension questions following the experimental items were answered correctly $80 \%$ of the time, indicating that participants were paying attention. Since the experimental items were not systematically probed and a differ-

Table 4

Mean Reading Times (in Milliseconds) and Standard Deviations (Experiment 2)

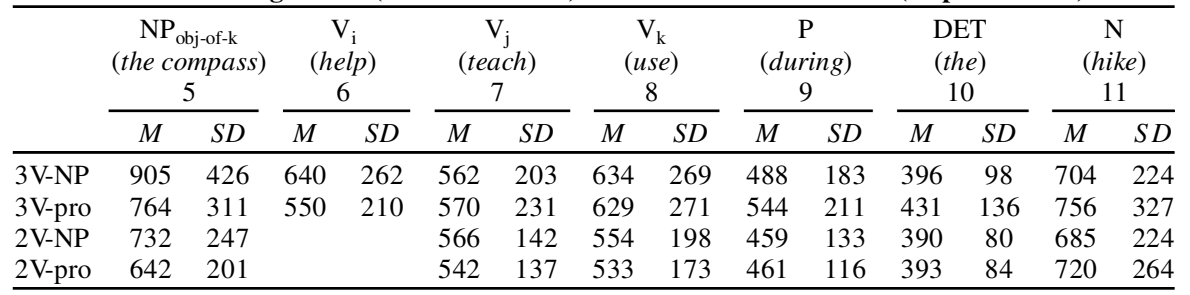

Note-3V-NP, 3-verb, full NP; 3V-pro, 3-verb, pronouns; 2V-NP, 2-verb, full NP; 2V-pro, 2-verb, pronouns. 


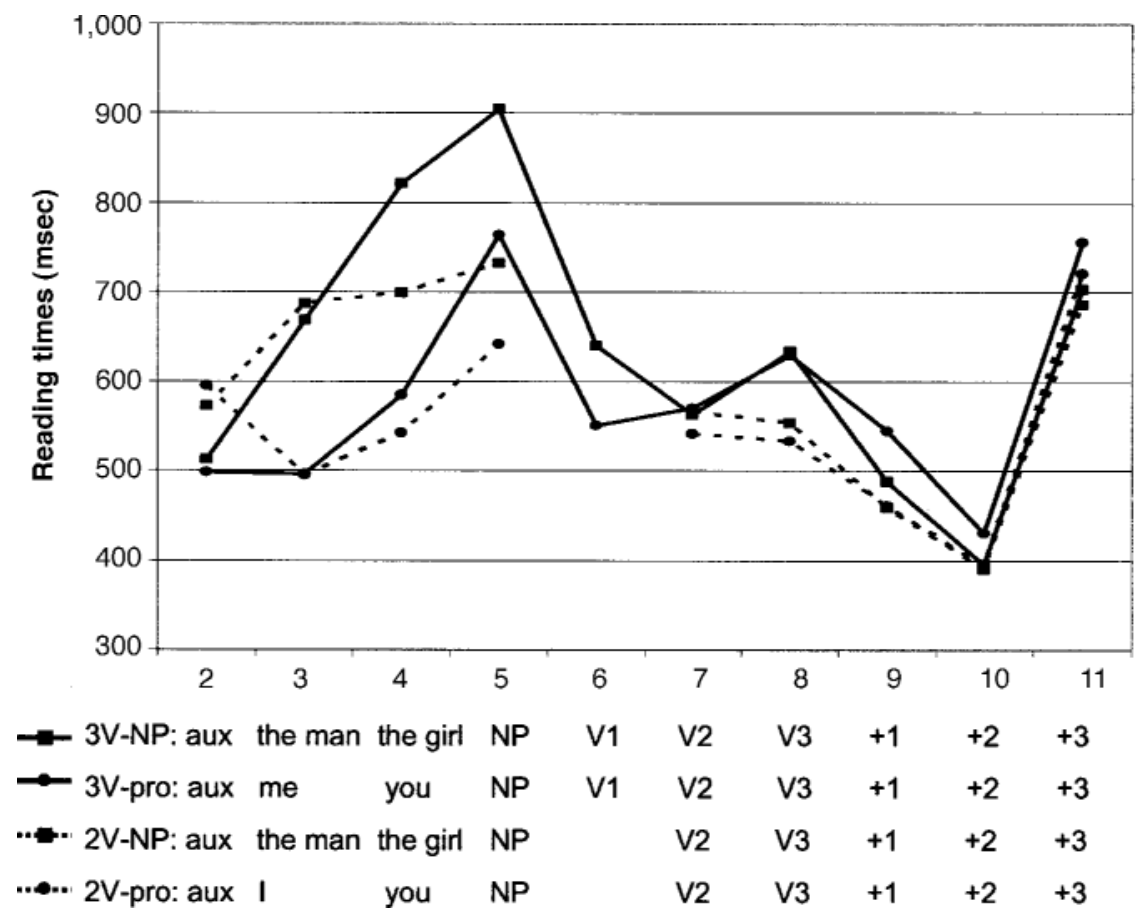

Figure 3. Experiment 2: Reading times in milliseconds for Segments 2-11 for each of the four conditions. Solid line, 3 -verb conditions; dotted, 2-verb; bullets, full NPs; squares, indexical pronouns. $V$, verb; $+1,+2,+3$, first, second, third segment after the last verb.

ent set of questions was presented for each participant, no statistical analyses were conducted on the comprehension data. Mean reading times for the sentence positions are given in Table 4 and Figure 3.

Position before the verbs (Segment 5). At Segment 5 , the pronoun conditions were read faster than the full-NP conditions $\left[F_{1}(1,35)=14.00, p<.001 ; F_{2}(1,28)=\right.$ $37.14, p<.001]$, and the 2 -verb conditions faster than the 3 -verb conditions $\left[F_{1}(1,35)=14.50, p<.001 ; F_{2}(1,28)=\right.$ $67.40, p<.001]$. However, there was no interaction between the type of NP and the number of Vs $\left[F_{1}(1,35)=\right.$ $\left.1.13, p=.295 ; F_{2}(1,28)=1.25, p=.273\right]$.

Verbs (Segments 6-8). Unlike in Experiment 1, the conditions differed at the first verb (Segment 6 in the 3verb condition; Segment 7 in the 2 -verb condition): Conditions with full NPs were read more slowly than conditions with pronouns [NP type: $F_{1}(1,35)=5.89, p<.05$; $\left.F_{2}(1,28)=11.49, p<.01\right]$, especially in the 3 -verb condition [NP type by number of Vs: $F_{1}(1,35)=4.40, p<$ $\left..05 ; F_{2}(1,28)=4.58, p<.05\right]$. Pairwise comparisons showed an effect of NP type in the 3 -verb condition $\left[F_{1}(1,35)=6.78, p<.05 ; F_{2}(1,28)=12.67, p<.001\right]$, but not in the 2 -verb condition $\left[F_{1}(1,35)=1.63, p=.210\right.$; $\left.F_{2}(1,28)=1.78, p=.193\right]$. This suggests that three full NPs intervening between the first verb and its subject had a detrimental effect on integration difficulty relative to the combination of two pronouns and a definite NP. At the penultimate verb (Segment 7 for both 2 - and 3 -verb conditions), no significant effects were found. The final verb
(Segment 8) was read more slowly in the 3 -verb relative to the 2 -verb conditions [number of Vs: $F_{1}(1,35)=9.19, p<$ $\left..01 ; F_{2}(1,28)=17.63, p<.001\right]$. The interaction of NP type and number of Vs was not significant for either penultimate or final verbs [penultimate verb: $F_{1}(1,35)=$ $.67, p=.42 ; F_{2}(1,28)=1.80, p=.19$; final verb: $\left.F_{1}(1,35)=.17, p=.19 ; F_{2}(1,28)=.13, p=.72\right]$.

Positions after verb (Segments 9-11). The 3-verb conditions were read more slowly than the 2 -verb at two word positions following the final verb [Segment 9: $F_{1}(1,35)=10.32, p<.01 ; F_{2}(1,28)=9.34, p<.01$; Segment 10: $F_{1}(1,35)=4.66, p<.05 ; F_{2}(1,28)=4.08, p=$ .053]. In addition, sentences with full NPs were read faster than those with pronouns in the 3-VP conditions, but the interaction of NP type by number of Vs was significant only by subjects in Segment $9\left[F_{1}(1,35)=5.21, p<.05\right.$; $\left.F_{2}(1,28)=2.98, p=.096\right]$, and by items in Segment 10 $\left[F_{1}(1,35)=2.28, p=.14 ; F_{2}(1,28)=4.41, p<.05\right] .^{3}$

\section{Discussion}

Corresponding to the results of Experiment 1, the conditions containing indexical pronouns were read faster than conditions with other types of NPs. The 3-verb conditions were read more slowly than the 2 -verb conditions at the verbs and the NP immediately preceding them. These findings are compatible with the complexity metric proposed in Gibson $(1998,2000)$. In contrast to the reading times in Experiment 1, reading times at the first verb were affected by the type of NP: Reading times in the 3-verb 
condition were longer for the full-NP conditions than for the pronouns. This contrast with Experiment 1 is unexpected under the complexity metric of Gibson (1998, 2000), which assumes that full NPs have the same effect as proper names on memory load and integration costs. The interaction of number of Vs with NP type in Experiment 2 is also problematic for the model proposed by Lewis (1996), which does not make a distinction between the types of NP used. The results are compatible with the model proposed by Gordon et al. (Gordon et al., 2001; Gordon et al., 2002): Compared with the conditionsin Experiment 1 and the pronoun conditions in the present experiment, the 3-verb full-NP condition may have induced more interference since it contained three nonintegrated NPs of the same type. We will discuss this further below.

\section{GENERAL DISCUSSION}

The aim of the present experiment was to examine the on-line processing of Dutch cross-serial dependencies and to test the cross-linguistic validity of current models of processing complexity by investigating the effects of NP type on the processing difficulty of these constructions. The results support a memory storage component along the lines of Gibson (1998) and an integration component along the lines of Gordon et al. (2001).

Before the verbs are encountered, information associated with the NPs needs to be stored in working memory. In the present experiments, we found that reading times before the verbs were longer for the full NPs and proper name conditions relative to the conditions containing indexical pronouns, even at a position that was physically the same across conditions (the NP preceding the first verb). These findings can be accounted for in terms of the storage component proposed in Gibson (1998). In addition, the 3 -verb conditions were read more slowly than the 2 -verb conditions at this pre-verb position. With each incoming NP, more structural predictions (verb or a trace position) need to be stored in working memory. Storage is harder if the intervening elements introduce new discourse referents, as in the full-NP and proper name conditions. However, the possibility that the increase in reading times at the NPs in the 3 -verb condition is due to revision processes, and hence could be accounted for in other models as well, cannot be excluded.

Reading times at the verbs were longer for 3 -verb versus the 2-verb sentences. This corresponds to the findings of Bach et al. (1986) and Dickey and Vonk (1996) that 2-verb sentences are easier to process than 3-verb sentences, and can be accounted for in both Gibson's model and the interference models (Gordon et al., 2001; Lewis, 1996). In Experiment 2, the first verb in 3-verb sentences showed an increase in reading times for the full-NP versus the indexical pronoun conditions. This interaction of NP type and number of verbs is unexpected under Lewis (1996), according to which only the syntactic function of the NPs in working memory, and not their type, affects interference in working memory. We did not find any difference in reading times at the verbs between sentences with firstand second-person pronouns, on the one hand, and proper names on the other (Experiment 1). This is not expected under the metric proposed in Gibson $(1998,2000)$, which predicts that integration at the verbs is easier with intervening indexical pronouns (since they denote old discourse referents) than with intervening proper names (new discourse referents). In order to accommodate the present results in a Gibson-type of model, the difference between NP types should not be binary (old vs. new), but rather continuous (e.g., along a Givenness hierarchy), as proposed in Warren and Gibson (2002). The difference between indexical pronouns and names on this scale may have been too small to affect processing difficulty at the verbs (Experiment 1), whereas the difference between indexical pronouns and full NPs may have been large enough to do so (Experiment 2). Note that such an account must assume that the effect of NP type is different for memory processes before the verbs and integration processes at the verbs.

An alternative account of the present results at the verbs posits interference through similarity (Gordon et al., 2001; Gordon et al., 2002). In this view, interference is not caused merely by similarity of syntactic function, but by similarity along multiple dimensions, among them the type of NP, case, or semantic features. In the present case, similarity of surface form is the most relevant dimension. Note that the full-NP conditions in Experiment 2 are the only conditions containing a sequence of three full NPs $\left(\mathrm{NP}_{\mathrm{j}}, \mathrm{NP}_{\mathrm{k}}, \mathrm{NP}_{\text {obj-of-k }}\right)$. As a consequence, retrieval of the NPs may have suffered more from interference through similarity in these conditions than in others, especially in the 3-verb condition, in which four NPs need to be retrieved and integrated with the verbs. Tentative support for interference by similarity is that the difficulty for the fullNP versus pronoun conditions seems to be affected by the surface similarity between $\mathrm{NP}_{\mathrm{j}}, \mathrm{NP}_{\mathrm{k}}$, and $\mathrm{NP}_{\text {obj-of-k }}$. In nearly all sentence materials, $\mathrm{NP}_{\mathrm{j}}$, and $\mathrm{NP}_{\mathrm{k}}$ were definite NPs starting with the determiner de ("the"-common gender). In 18 item sets, the third $\mathrm{NP}, \mathrm{NP}_{\text {obj-of-k }}$, also contained the determiner $d e$; in the remaining materials, it had a different determiner (e.g., het, "the"-neuter gender; or een, "a"-all genders). Numerically, all de items showed a larger disadvantage for the full-NP versus the pronoun conditions in the 3-verb sentences [means at first verb: $d e$ items, 3V-NP, $659 \mathrm{msec}$; $3 \mathrm{~V}$-pronoun, $545 \mathrm{msec}$; other items, 3V-NP, $612 \mathrm{msec}$; $3 \mathrm{~V}$-pronoun, $552 \mathrm{msec}$ ]. In the 2verb condition, the items with a determiner other than de even showed faster reading times for the full-NP sentences relative to the pronoun $[d e, 2 \mathrm{~V}-\mathrm{NP}, 595 \mathrm{msec}, 2 \mathrm{~V}-$ pronoun, $538 \mathrm{msec}$; other, $2 \mathrm{~V}-\mathrm{NP}, 528 \mathrm{msec} ; 2 \mathrm{~V}$ pronoun, $541 \mathrm{msec}$. This pattern also held when materials were restricted to singular $\mathrm{NP}_{\text {obj-of-k }}$, comparing items in which $\mathrm{NP}_{\text {obj-of-k }}$ started with $d e$ (common gender, $n=8$ ) versus het (neuter, $n=7$ ) [means at first verb for 3 -verb clauses: $d e$-items, NP, $702 \mathrm{msec}$, pronoun $537 \mathrm{msec}$; het, NP, $644 \mathrm{msec}$, pronoun, $575 \mathrm{msec}$; means at first verb for 2-verb clauses: de-items, NP, $636 \mathrm{msec}$, pronoun $551 \mathrm{msec}$; het, 
$\mathrm{NP}, 508 \mathrm{msec}$, pronoun, $547 \mathrm{msec}$. Note that in most cases, $\mathrm{NP}_{\text {obj-of-k }}$ referred to an inanimate entity, whether it was preceded by de or het. These observations suggest that there is an effect of surface similarity (determiner) or similarity in syntactic gender, which can be accounted for only in an interference by similarity model. Further research is needed to more explicitly test the interference model. One prediction this model makes is that processing is harder when $\mathrm{NP}_{\mathrm{j}}$, and $\mathrm{NP}_{\mathrm{k}}$ are both pronouns, names, or full NPs than when the NPs are each of a different type (e.g., pronoun-full NP, full NP-pronoun). This pattern is not predicted by models of the kind proposed by Gibson and Lewis.

In sum, the present research is one of the first to examine the on-line processing of cross-serial dependencies in Dutch, testing the cross-linguistic generalizability of three leading theories of processing difficulty. Results showed that (1) 2-verb sentences are easier than 3-verb sentences, even at positions before the verb; (2) storage is easier for indexical pronouns than for proper names and full NPs (see Gibson, 1998, 2000); (3) integration at the verbs is not easier for indexical pronouns versus proper names; and (4) integration at the first verb in 3-verb sentences is harder for full NPs than for indexical pronouns. The latter two findings cannot readily be accounted for in the processing models proposed by Gibson $(1998,2000)$ or Lewis (1996) but are compatible with a model in which integration is hindered by interference through similarity (Gordon et al., 2001; Gordon et al., 2002).

\section{REFERENCES}

BAByonishev, M., \& GibSON, E. (1999). The complexity of nested structures in Japanese. Language, 75, 423-450.

Bach, E., Brown, C., \& MARsLen-Wilson, W. (1986). Crossed and nested dependencies in German and Dutch: A psycholinguisticstudy. Language \& Cognitive Processes, 1, 249-262.

BENNIS, H., \& HOE KSTRA, T. (1989). Generatieve grammatika [generative grammar]. Dordrecht: Foris.

BE VER, T. G. (1970). The cognitive basis of linguistic structures. In J. R. Hayes (Ed.), Cognition and the development of language (pp. 279362). New York: Wiley.

DiCKeY, M. W., \& VONK, W. (1996). Center-embedded structures in Dutch: An on-line study. Poster presented at the ninth CUNY conference on human sentence processing.

GiBSON, E. (1998). Linguistic complexity: Locality of syntactic dependencies. Cognition, 68, 1-76.

GiBson, E. (2000). The dependency locality theory: A distance-based theory of linguistic complexity. In A. Marantz, Y. Miyashita, \& W. O'Neil (Eds.), Image, language, brain: Papers from the first mind articulation project symposium (pp. 95-126). Cambridge, MA: MIT Press.

Gordon, P. C., Hendrick, R., \& Johnson, M. (2001). Memory inter- ference during language processing. Journal of Experimental Psychology: Learning, Memory, \& Cognition, 27, 1411-1423.

Gordon, P. C., Hendrick, R., \& Levine, W. H. (2002). Memory-load interference in syntactic processing. Psychological Science, 13, 425430.

Hagstrom, P., \& RheE, J. (1997). Differences between Korean and Japanese processing overload. Journal of Psycholinguistic Research, 26, 189-206.

HAWKINS, J. A. (1994). A performance theory of order and constituency. New York: Cambridge University Press.

KAAN, E. (1992). A minimalist approach to extraposition. Unpublished MA thesis, University of Groningen.

KiMBALL, J. (1973). Seven principles of surface structure parsing in natural language. Cognition, 2, 15-47.

Koster, J. (1975). Dutch as an SOV language. Linguistic Analysis, 1, 111-136.

LEWIS, R. L. (1996). Interference in short-term memory: The magical number two (or three) in sentence processing. Journal of Psycholinguistic Research, 25, 93-113.

LEWIS, R. L., \& NAKAYAMA, M. (2001). Syntactic and positional similarity effects in the processing of Japanese embeddings. In M. Nakayama (Ed.), Sentence processing in East Asian languages (pp. 85113). Stanford, CA: CSLI.

Miller, G. A., \& CHOMSKY, N. A. (1963). Finitary models of language users. In R. D. Luce, R. R. Bush, \& E. Galanter (Eds.), Handbook of mathematical psychology (Vol. 2, pp. 419-491). New York: Wiley.

STABLER, E. P. (1994). The finite connectivity of linguistic structures. In C. Clifton, L. Frazier, \& K. Rayner (Eds.), Perspectives on sentence processing (pp. 303-336). Hillsdale, NJ: Erlbaum.

VASISHTH, S. (2002). Working memory in sentence comprehension: Processing Hindi center embeddings. Unpublished $\mathrm{PhD}$ dissertation, Ohio State University.

VAsishth, S., \& KruiJfF, G. J. M. (2000). Processing as abduction: A sentence processing model. Paper presented at the workshop on linguistic theory and grammar implementation, Birmingham, U.K.

WARREN, T., \& GIBSON, E. (2002). The influence of referential processing on sentence complexity. Cognition, 85, 79-112.

ZWART, C. J. W. (1997). Morphosyntax of verb movement: A minimalist approach to the syntax of Dutch. Dordrecht: Kluwer.

\section{NOTES}

1. We assume a linguistic analysis according to which all NPs are moved out of their VPs to an A-position (Kaan, 1992; Zwart, 1997). Even though only NP1 is strictly speaking in a subject position (AgrSP), the other NPs can qualify to be interpreted as the thematic subject of the downstream predicates, causing interference at the point of retrieval.

2. This cutoff may appear rather stringent. To ensure that we did not trim away any effects, we ran additional analyses using a cutoff criterion of mean plus $3 S D$, calculated over all participants and conditions, which affected $2 \%$ of the data. The outcomes were qualitatively similar to those reported in the main text. The same is true for Experiment 2.

3. In both Experiments 1 and 2, the 3-verb condition was harder to process (at least, numerically) toward the end of the sentence with indexical pronouns than with proper names or full NPs. This effect was not predicted by any of the models discussed here.

(Manuscript received December 3, 2002;) revision accepted for publication September 4, 2003.) 